\title{
C-Type Lectin Domain Family 10 Member A
}

National Cancer Institute

\section{Source}

National Cancer Institute. C-Type Lectin Domain Family 10 Member A. NCI Thesaurus. Code 122766.

C-type lectin domain family 10 member A (316 aa, $35 \mathrm{kDa}$ ) is encoded by the human CLEC10A gene. This protein is involved in the regulation of adaptive and innate immune responses. 